\title{
CAMPUR KODE SIARAN RADIO MOST FM PENYIAR ARI DI KOTA MALANG
}

\author{
Heny Kusuma Widyanigrum \\ Fakultas Keguraun dan Ilmu Pendidikan \\ Universitas PGRI Madiun \\ h3nnycecan@gmail.com
}

\begin{abstract}
Abstrak: Penelitian ini mendeskripsikan wujud kode dan campur kode pada tuturan yang dilakukan oleh penyiar radio Most FM di Kota Malang. Tuturan dalam siaran Most FM tersebut terjadi peristiwa campur kode, baik itu campur kode ke dalam atau pun campur kode ke luar. Peralihan bahasa yang terjadi, yaitu bahasa Inggris dan Jawa. Jenis penelitian ini adalah kualitatif deskriptif. Data dalam penelitian ini adalah siaran radio Most FM yang dilakukan oleh penyiar Ari di Kota Malang. Teknik pengumpulan data dilakukan dengan teknik simak dan catat. Metode analisis data yang digunakan adalah metode padan. Hasil penelitian menunjukkan peralihan bahasa yang terjadi, yaitu bahasa Inggris dan Jawa. Selian itu, banyak faktor munculnya terjadinya campur kode, antara lain supaya terkesan santai atau akrab dengan pendengar; lebih populer, bergengsi, dan singkat.
\end{abstract}

Kata Kunci: campur kode, tuturan, siaran radio

Abstract: This study described the code feature and code mixing conducted by the broadcaster of Most FM radio in Malang. The speech in the broadcast of Most FM provided the opportunity for code mixing to occur, both inward and outward. The language switch process occurred in the study included English and Javanese. This study was a descriptive qualitative study. Data was radio broadcast used by Ari, a broadcaster of Most FM radio in Malang. The data collection was by listen and record technique. Data analysis technique was match technique. The result of the study showed there was language switch occurred between English and Javanese. That there were plenty factor that initiated the code mixing, such as to feel more relax or friendly and familiar with the audience; to be more popular, prestigious and brief.

Keywords: code mixing, speech, radio broadcast

\section{PENDAHULUAN}

Bahasa merupakan alat komunikasi yang bebas yang dipergunakan oleh anggota masyarakat untuk berinteraksi. Sebagai alat komunikasi, bahasa mampu melakukan kegiatan, seperti saling belajar dari orang lain dan saling memahami orang lain. Melalui bahasa, seseorang akan dapat mengungkapkan sesuatu yang ingin dikemukakannya, sehingga lawan tuturnya akan memahami maksud ungkapan yang dikemukakan oleh lawan tutur tersebut. Jadi, manusia tidak dapat terlepas dari bahasa.

Seseorang melakukan proses interaksi dengan sesamanya, dapat memakai lebih dari satu bahasa dan mengakibatkan terjadinya kontak antarbahasa. Keragaman bahasa yang ditemui di Indonesia ini disebabkan karena adanya faktor budaya, faktor sejarah, dan faktor perbedaan demografi. Keragaman bahasa di masyarakat menyebabkan terciptanya masyarakat bilingual atau multilingual yang memiliki dua bahasa atau 
lebih, sehingga mereka harus memilih bahasa atau variasi bahasa mana yang harus digunakan dalam sebuah situasi.

Kedwibahasaan atau bilingualisme ialah kebiasaan menggunakan dua bahasa dalam interaksi dengan orang lain. Menurut Mackey dan Fishman (Chaer \& Agustina, 2004: 84-85), bilingualisme sebagai penggunaan dua bahasa oleh seorang penutur dalam pergaulannya dengan orang lain secara bergantian. Selain istilah bilingualisme dengan segala jabarannya ada juga istilah multilingualisme (dalam bahasa Indonesia disebut juga keanekabahasaan) yakni keadaan digunakannya lebih dari dua bahasa oleh seseorang dalam pergaulannya dengan orang lain secara bergantian.

Salah satu fenomena kedwibahasaan adalah adanya campur kode. Menurut Sarwiji (2007: 113), menjelaskan campur kode adalah penggunaan satuan bahasa dari bahasa satu ke bahasa yang lain untuk memperluas gaya dan ragam bahasa, termasuk di dalamnya pemakaian kata, klausa, idiom, dan sapaan. Campur kode ada sebuah kode utama yang digunakan dan memiliki fungsi dan keotonomiannya, sedangkan kode-kode lain yang terlibat dalam peristiwa tutur hanya berupa serpihan-serpihan saja, tanpa fungsi sebagai sebuah kode (Chaer \& Agustina, 2004: 151). Misalnya, seorang penutur yang banyak menggunakan bahasa Indonesia dan menyelipkan bahasa-bahasa daerahnya dapat dikatakan melakukan campur kode.

Campur kode terjadi karena ketergantungan penutur terhadap pemakaian bahasa. Ciri yang menonjol dalam campur kode ini adalah kesantaian atau situasi informal. Dalam situasi berbahasa yang formal, peristiwa campur kode kurang mendominasi. Kalau pun terdapat campur kode dalam keadaan demikian, itu disebabkan tidak adanya ungkapan yang terdapat dalam bahasa yang sedang dipakai itu, sehingga perlu memakai kata atau ungkapan dari bahasa asing yang bersangkutan.

Radio adalah sebuah teknologi yang digunakan untuk mengirim sinyal dengan gelombang tertentu, kita mengenalnya dengan gelombang elektromagnetik yang merupakan hasil modulasi dan radiasi dari elektromagnetik. Siaran radio lahir karena perkembangan teknologi elektronik yang diaplikasikan ke dalam bentuk teknologi komunikasi dan informasi serta dirancang untuk keperluan proses komunikasi antarmanusia dengan cara pemancaran atau transmisi melalui gelombang elektromagnetik. Setiap mata acara siaran direncanakan, diproduksi, dan disajikan kepada pendengar dengan isi pesan yang bersifat informatif, edukatif, persuasif, stimulatif, dan komunikatif (Wahyudi, 1996: 7).

Penggunaan campur kode dari bahasa satu ke bahasa lain memang sulit untuk dihindari dan selalu ada, sepanjang penutur masih menggunakan bahasa itu secara bergantian. Salah satunya sering dijumpai dalam siaran radio yang dibawakan oleh penyiar. Seorang penyiar menjadi ujung tombak dalam proses menyampaikan informasi dan hiburan kepada pendengar. Melalui penyiarnya, radio harus mampu menjalin komunikasi yang baik dengan pendengar, sehingga mudah dimengerti dan komunikasi akan berjalan efektif.

Bahasa penyiar radio tidak dapat lepas dari gejala campur kode. Dengan berbagai bahasa yang dimilikinya, penyiar radio dapat dengan mudah mengganti bahasa yang digunakan, bahkan menggunakan bahasa tersebut secara bergantian sesuai dengan situasi, kondisi, dan tujuan tuturannya. Bahasa inti yang digunakan dalam acara musik ada supaya mudah dipahami adalah bahasa Indonesia, tetapi dalam tuturannya penyiar sering mencampurkan bahasa tersebut dengan kode bahasa lain.

Penelitian ini bertujuan memaparkan wujud kode dan campur kode pada tuturan yang dilakukan oleh penyiar radio Most FM di Kota Malang. Tuturan dalam siaran Most FM tersebut terjadi peristiwa campur kode, baik itu campur kode ke dalam atau pun campur kode ke luar. Tuturan dalam penyiaran radio Most FM di Kota Malang saat acara musik, penyiar menggunakan bahasa inti, yaitu bahasa Indonesia. Akan tetapi, saat menyapa para pendengarnya melalui telepon, 
penyiar sering menyelipkan bahasa dialek Malang yang sering disebut bahasa "walikan". Unsur bahasa lain selain bahasa dialek daerah, yaitu bahasa Inggris yang sering digunakan dalam lingkup penyiaran. Dengan demikian, pemakaian bahasa pada tuturan penyiar acara musik radio Most FM memperlihatkan ciriciri dan mengalami peristiwa kebahasaan yang menarik untuk dikaji.

\section{METODE}

Jenis penelitian ini menggunakan pendekatan kualitatif deskriptif. Peneliti memaparkan hasil penelitiannya dengan katakata. Data dalam penelitian ini adalah siaran radio Most FM yang dilakukan oleh penyiar Ari di Kota Malang. Teknik pengumpulan datanya yaitu dengan teknik simak dan catat. Setelah semua terkumpul secara lengkap, dilakukan analisis data. Metode analisis data yang peneliti gunakan adalah metode padan. Penggunaan metode ini didasarkan pada asumsi bahasa yang diteliti memiliki hubungan dengan hal-hal yang ada di luar bahasa yang bersangkutan.

\section{HASIL DAN PEMBAHASAN}

Hasil penelitian menunjukkan adanya peristiwa campur kode serta faktor penyebabnya. Bentuk campur kode yang terdapat pada siaran musik Most FM Malang campur kode ke dalam dan luar yang berbentuk kata, frasa, baster, dan klausa. Sebelum penjelasan hasil penelitian, berikut ini dipaparkan deskripsi data primer dan sekunder pada siaran musik Most FM Malang.

Tabel 1. Deskripsi Data Primer dan Sekunder Siaran Musik Most FM Malang

\begin{tabular}{|c|c|c|}
\hline No & Data Primer & Data Sekunder \\
\hline 1 & $\begin{array}{l}\text { "Baiklah friend, tadi baru saja kita putar single } \\
\text { lagu Creed Don't Stop Dancing }\end{array}$ & $\begin{array}{l}\text { Friend (teman) } \\
\text { Single (lagu) }\end{array}$ \\
\hline 2 & $\begin{array}{l}\text { "Terus, siapa lagi yang di bawahnya si Puspa. } \\
\text { Loading ya rek. }\end{array}$ & $\begin{array}{l}\text { Loading (pemuatan) } \\
\text { Rek (panggilan akrab masyarakat } \\
\text { Malang) }\end{array}$ \\
\hline 3 & $\begin{array}{l}\text { "yang pengen request lagunya Ungu-Dengan } \\
\text { Nafasmu, check it dot. }\end{array}$ & $\begin{array}{l}\text { Pengen (ingin) } \\
\text { Request (meminta), } \\
\text { Check it dot (periksalah ini) }\end{array}$ \\
\hline 4 & $\begin{array}{l}\text { "Masih bersama Ari di sini, request tempat } \\
\text { buat umak yang kepengen single favoritnya } \\
\text { kamu, boleh single Indonesia maupun single } \\
\text { mancanegara, di request di land topnya Most } \\
\text { FM atau di land Facebook Most FM" }\end{array}$ & $\begin{array}{l}\text { Request (meminta) } \\
\text { Land top (masuk untuk bergabung) } \\
\text { Single (lagu) } \\
\text { Umak (kamu) }\end{array}$ \\
\hline 5 & $\begin{array}{l}\text { "Kepengen request lagunya apa ni? Piyu? yang } \\
\text { mana? sakit hati? Cieeee, singlenya buat } \\
\text { sapa? }\end{array}$ & $\begin{array}{l}\text { Kepengen (menginginkan) } \\
\text { Single (lagu) } \\
\text { Sapa (siapa) }\end{array}$ \\
\hline 6 & Oke, thank you. Walaikumsalam. & Thank you (terima kasih) \\
\hline 7 & $\begin{array}{l}\text { Bingung mau request lagunya sapa? semuanya } \\
\text { udah yaa.. request lagunya Agnes Monica } \\
\text { featuring Elena deh yang Broken Angel. }\end{array}$ & $\begin{array}{l}\text { Featuring (bersama) } \\
\text { Request (meminta) } \\
\text { Udah (sudah) }\end{array}$ \\
\hline 8 & $\begin{array}{l}\text { "buat kalian semua sebentar lagi akan ayas } \\
\text { play Sherina Geregetan" }\end{array}$ & $\begin{array}{l}\text { Ayas play (saya mainkan) } \\
\text { the most wanted (yang paling dinanti) }\end{array}$ \\
\hline 9 & "tetep stay turn di Most FM ya" & Stay turn (tetap di) \\
\hline 10 & $\begin{array}{l}\text { "Yowesslaah... Dengan siapa di sana? Ayune } \\
\text { pake banget pasti.." }\end{array}$ & $\begin{array}{l}\text { Yoweslah (ya sudahlah) } \\
\text { Ayune (cantiknya) }\end{array}$ \\
\hline 11 & "lagu ini cukup ngehit minggu ini, monggo" & $\begin{array}{l}\text { Hit (populer) } \\
\text { Monggo (silahkan) }\end{array}$ \\
\hline
\end{tabular}




\begin{tabular}{|c|c|c|}
\hline No & Data Primer & Data Sekunder \\
\hline 12 & "Chart minggu ini masih bertahan yaitu.." & Chart (grafik) \\
\hline 13 & $\begin{array}{l}\text { Waah, mbulet arek iki.. sapa lo? gak ayas } \\
\text { putarkan nanti.. (tertawa) }\end{array}$ & $\begin{array}{l}\text { Mbulet arek iki (bermasalah anak ini) } \\
\text { Gak (tidak) }\end{array}$ \\
\hline 14 & $\begin{array}{l}\text { "anyway, so jangan beralih channel dari Most } \\
\text { FM" }\end{array}$ & $\begin{array}{l}\text { Anyway (ngomong-ngomong) } \\
\text { so (jadi) } \\
\text { channel (saluran) }\end{array}$ \\
\hline 15 & "ini lagu best new release" & Best new release (yang terbaru) \\
\hline 16 & "Most FM cool station" & Cool station (stasiun radio keren) \\
\hline 17 & $\begin{array}{l}\text { "well, pastinya thank you terima kasih buat } \\
\text { sahabat setia semuanya, thank you buat } \\
\text { kesetiaan kalian and tetap tangames. Dan kalo } \\
\text { gitu, aku puterin satu single yang sudah } \\
\text { request di land facebook. Now, Bondan } \\
\text { Prakoso featuring Fade } 2 \text { Black-Tak Ada yang } \\
\text { Sempurna. }\end{array}$ & $\begin{array}{l}\text { Well (baiklah) } \\
\text { Now (sekarang) } \\
\text { Tangames (semangat) } \\
\text { And (dan) } \\
\text { Thank you (terima kasih) } \\
\text { Single (lagu) }\end{array}$ \\
\hline & Jumlah & $\begin{array}{l}\text { Kata berjumlah } \mathbf{2 0} \text {, yaitu friend, single, } \\
\text { loading, pengen, request, kepengen, } \\
\text { yoweslah, ayune, chart, channel, well, } \\
\text { now, hit, monggo, umak, tangames, rek, } \\
\text { sapa, udah, dan and. } \\
\text { Frasa berjumlah } 7 \text {, yaitu land top, thank } \\
\text { you, cool station, best new release, } \\
\text { anyway, the most wanted, dan stay turn. } \\
\text { Klausa hanya } 1 \text {, yaitu gak ayas } \\
\text { Baster ada } 2 \text {, yaitu (1) land topnya dan } \\
\text { (2) singlenya. }\end{array}$ \\
\hline
\end{tabular}

Sumber : http://www.youtube.com/watch? $v=-s I T T v-b t N E$

\section{Pembahasan}

Tuturan penyiar pada acara musik radio Most FM di Malang tersebut terjadi adanya campur kode, baik campur kode ke dalam maupun campur kode ke luar. Hal itu disebabkan karena pada umumnya seorang penyiar adalah dwibahasawan. Jarang terjadi penyiar hanya bertutur satu bahasa saja, kecuali pada acara yang resmi seperti siaran radio berita. Akan tetapi, berhubung siaran radio yang dikaji adalan siaran musik, maka campur kode pun sulit dihindarkan. Bentuk campur kode yang terdapat pada siaran musik Most FM Malang campur kode ke dalam dan luar yang berbentuk kata, frasa, baster, dan klausa. Berikut data dan analisis dari bentuk campur kode tersebut.

\section{Campur Kode Berbentuk Kata}

Menurut Chaer (2007: 62) kata adalah unsur bahasa yang diucapkan atau dituliskan yang merupakan perwujudan kesatuan perasaan dan pikiran yang dapat digunakan dalam berbahasa, atau deretan huruf yang diapit oleh dua spasi dan mempunyai arti. Campur kode berbentuk kata merupakan penyisipan serpihan bahasa berupa kata asing atau penutur ke struktur bahasa penutur. Campur kode berbentuk kata yang digunakan dalam siaran Most FM Malang meliputi penyisipan bahasa Inggris, bahasa Jawa, dan bahasa "walikan" khas Malang. Berikut ini contoh data beserta analisisnya.

1) Lagu ini cukup ngehit minggu ini, monggo.

2) "Baiklah friend, tadi baru saja kita putar single lagu Creed Don't Stop Dancing.

3) Yoweslah... Dengan eneng siapa di sana? Ayune pake banget pasti.

4) "Masih bersama Ari di sini, request tempat buat umak yang kepengen single favoritnya kamu.

5) .... buat kesetiaan kalian and tetap tangames. 
Data di atas terdapat campur kode berbentuk kata, yaitu friend, single, request, monggo, yoweslah, ayune, umak dan tangames. Kata friend, single, request itu merupakan bahasa Inggris yang sering didengar oleh kalangan pendengar remaja dalam acara musik di siaran radio yang artinya teman, lagu, dan meminta. Kata monggo, yoweslah, dan ayune merupakan bahasa Jawa yang juga sering dijumpai dengan arti silakan, biarlah, dan cantik sekali. Kata umak dan tangames merupakan dialek daerah Malang yang sering disebut bahasa walikan.

Terjadinya campur kode berbentuk kata yang berbahasa Inggris, Jawa, dan bahasa dialek atau walikan daerah Malang dapat disebabkan beberapa faktor, yaitu situasi dan lawan yang diajak komunikasi. Berhubung acara tersebut adalah acara musik untuk kalangan remaja, maka situasinya lebih santai atau informal. Pendengar yang request atau minta lagu untuk diputarkan juga kalangan remaja. Jadi, tujuan penyiar menggunakan tiga bahasa tersebut agar tercipta suasana yang akrab, sehingga tidak terkesan tegang.

\section{Campur Kode Berbentuk Frasa}

Chaer (2011: 222), frasa adalah satuan gramatikal yang berupa gabungan kata yang bersifat non predikatif atau gabungan kata yang mengisi salah satu fungsi sintaksis dalam kalimat. Campur kode berbentuk frasa merupakan penyisipan serpihan bahasa berupa frasa bahasa asing atau serumpun ke dalam struktur bahasa penutur. Campur kode berbentuk frasa yang digunakan pada siaran Most FM Malang hanya penyisipan berbahasa Inggris ke dalam struktur bahasa Indonesia. Berikut ini contoh data beserta analisisnya.

1) "ini lagu best new release"

2) "Most FM cool station"

3) "tetep stay turn di Most FM ya"

Pada tuturan di atas mengalami campur kode berbentuk frasa, yaitu best new release, cool station, dan stay turn yang berasal dari bahasa
Inggris. Penggunaan frasa tersebut sebenarnya dapat diganti dengan bahasa Indonesia oleh penutur. Arti dari tiga frasa tersebut yaitu (1) yang terbaru (best new release, (2) stasiun yang keren (cool station), dan (3) tetap di... (stay turn). Penyiar menggunakan kata-kata tersebut dapat disebabkan beberapa faktor, yaitu kebiasaan, lebih populer, dan lebih ringkas. (1) Kebiasaan, penyiar adalah seorang dwibahasawan, maka dari itu dapat menjadi suatu kebiasaan jika saat acara musik tersebut menggunakan istilah-istilah asing di bidang penyiaran; (2) lebih populer, penggunaan bahasa Inggris lebih populer, sehingga masyarakat lebih suka menggunakannya termasuk penyiar radio; dan (3) lebih ringkas, suatu istilah jika diterjemahkan dalam bahasa Indonesia dapat menjadi lebih panjang, sehingga mempersulit mengingatnya.

\section{Campur Kode Berbentuk Baster}

Campur kode berbentuk baster merupakan penyisipan gabungan bahasa asli penutur dengan bahasa penutur. Campur kode baster yang digunakan adalah penyisipan gabungan bahasa Indonesia dengan bahasa Inggris, dan gabungan bahasa Indonesia dengan bahasa Jawa.

Berikut ini contoh data beserta analisisnya.

1) "Masih bersama Ari di sini, request tempat buat umak yang kepengen single favoritnya kamu, boleh single Indonesia maupun single mancanegara, direquest di land topnya Most FM atau di land Facebook Most FM"

2) "Kepengen request lagunya apa ni? Piyu? yang mana? sakit hati? Cieeee, singlenya buat sapa.

Pada tuturan di atas mengalami campur kode berbentuk baster yang dilakukan penyiar radio musik Radio Most FM Malang. Hal tersebut dikarenakan serpihan yang disisipkan merupakan gabungan asli dengan bahasa asing. Terdapat dua kata, yaitu kata bahasa Inggris dan kata asli bahasa Indonesia. Ketika kedua kata tersebut 
digabung maka akan membentuk baster. Baster tersebut adalah land top-nya yang artinya masuk untuk bergabungnya dan single-nya yang artinya lagunya. Campur kode tersebut dikatakan baster karena kata land top dan single adalah kata asli bahasa Inggris, kemudian disandingkan dengan partikel -nya yang merupakan partikel bahasa Indonesia.

Era globalisasi ini, penggunaan unsur asing, khususnya bahasa Inggris semakin marak di mana-mana. Meskipun sudah ada padanannya dalam bahasa Indonesia, masyarakat kita lebih suka memakai istilah bahasa Inggris tersebut. Ini dikarenakan masyarakat telah mengenal lebih dahulu istilah bahasa Inggrisnya daripada padanan kata bahasa Indonesianya, sehingga yang terasa akrab di telingalah yang lebih dipilih.

\section{Campur Kode Berbentuk Klausa}

Campur kode berbentuk klausa merupakan penyisipan unsur-unsur dari bahasa asing atau serumpun berupa penyisipan satuan gramatikal berupa kelompok kata yang sekurang-kurangnya terdiri dari subjek dan predikat, serta mempunyai potensi untuk menjadi kalimat ke dalam struktur bahasa penutur. Campur kode berbentuk klausa yang digunakan dalam siaran Most FM Malang berupa penyisipan-penyisipan klausa bahasa Jawa dialek Malang. Berikut ini contoh data beserta analisisnya.

1) Waah, mbulet arek iki..sapa lo? gak ayas putarkan nanti..(tertawa)

Pada tuturan di atas mengalami campur kode berwujud klausa, yaitu gak ayas. Penggunaan klausa gak ayas dapat diganti dengan bahasa Indonesia. Namun, dalam tuturan ini penutur lebih memilih menggunakan klausa gak ayas karena beranggapan klausa tersebut lebih familiar dan lebih sering digunakan daripada arti dalam bahasa Indonesia. Apabila bentuk klausa gak ayas diganti ke dalam bahasa Indonesia menjadi tidak saya.

\section{KESIMPULAN}

Berdasarkan hasil analisis data tentang campur kode dalam tuturan acara musik siaran Radio Most FM Malang tuturan penyiar acara musik radio Most FM ditemukan 30 peristiwa campur kode, yaitu 20 berbentuk kata, 7 berbentuk frasa, 1 berbentuk klausa, dan 2 berbentuk baster. Dari data tersebut, terdapat peristiwa campur kode baik sebagai akibat dari adanya kontak bahasa dan situasi bilingualisme. Terjadinya campur kode tersebut tidak dapat dihindari karena penutur yang terlibat merupakan dwibahasawan atau multibahasawan, yaitu dari bahasa Inggris, Jawa, dan dialek daerah Malang. Hal ini sangat penting karena orang dapat dikatakan berhasil berkomunikasi apabila dapat memenuhi pemakaian bahasa yang didukung unsur lain dari bahasa. Peralihan bahasa yang terjadi, yaitu bahasa Inggris dan bahasa Jawa. Banyak faktor munculnya terjadinya campur kode, antara lain supaya terkesan santai atau akrab dengan pendengar, lebih populer, bergengsi, dan singkat.

\section{DAFTAR PUSTAKA}

Chaer, Abdul \& Agustina, L. (2004). Sosiolinguistik Perkenalan Awal. Jakarta: PT. Rineka Cipta.

Chaer, A. (2007). Kajian Bahasa: Struktur Internal, Pemakaian, dan Pembelajaran. Jakarta: PT. Rineka Cipta.

Chaer, A. (2011). Psikolinguistik Kajian Teoretik. Jakarta: PT. Rineka Cipta.

Sarwiji, S. (2007). Serbalinguistik Mengupas Pelbagai Praktik Berbahasa. Salatiga: Widya Sari.

Wahyudi, J. B. (1996). Dasar-dasar Jurnalistik Radio dan Televisi. Jakarta: Pustaka Utama. 